\title{
Air pollution monitoring and its role in public health
}

Air pollution monitoring is an
important factor in air quality
management. Both stablished
long-term monitoring stations
and short-term seasonal
atmospheric field measurements
are required to understand how
atmospheric chemistry changes
in response to air pollution
regulation. Professor Schwab
and his team from the University
at Albany maintain long-term
rural monitoring stations as
well as highly specific mobile air
pollution measurements with the
aim of using their data to help
inform and improve air quality
regulation policies and improve
public health.

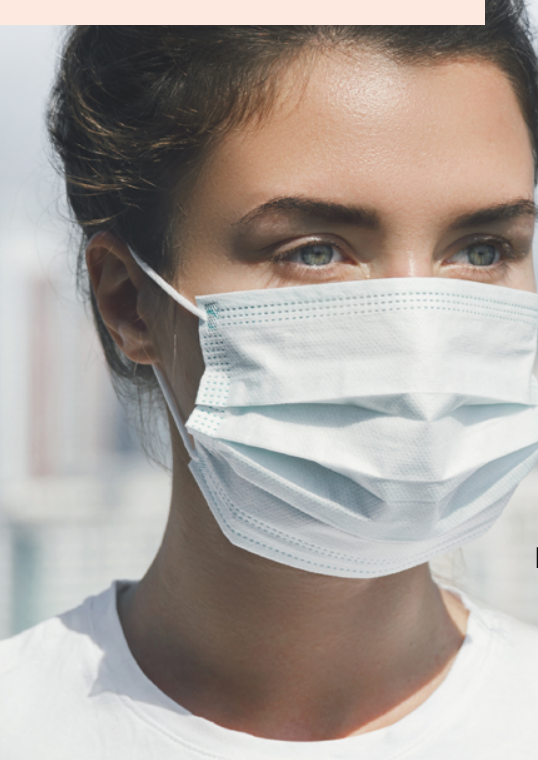

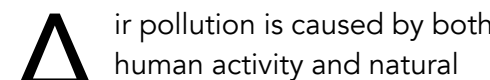

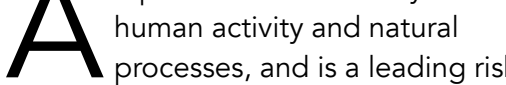
factor for mortality worldwide. Air is considered polluted when it contain excessive quantities of chemicals, such as sulphur compounds, nitrogen oxides, volatle organic compounds, ozne and chlorofluorocarbons (CFCs). of paricula te mater, which consists combustion or biological sources.

Attempts are made to limit the pollutants released into the atmosph through best practice, regulation and policy. However air pollution still leads to millions of deaths around the world every year. According to the World Health Organization, there were 4 million premature deaths globally due to exposure to fine particles in 2016. Densely populated cities, such as Mexico City, Beijing, and Delhi

often suffer from smog, which can trap

Air pollution negatively affects

health. It can cause breathing difficulties and major respiratory

infections, exacerbate lung diseases such as asthma, and contribute to lung cancer. Pollution can also trigger cardiovascular problems such as heart attacks and strokes.

Professor James Schwab and his team at the Atmospheric Sciences Research Center of the University at Albany have been making measurements of gas and aerosol (solid particles or liquid drops within air pollutants for many years.
They combin measurements taken over very long-term, multiyear periods with those taken during short-term field deployments. They hope these findings will be used to aid policymakers in air pollution regulation to improve ir quality for the general public.

WHY LONG-TERM AND SHORT-TERM? The relationships between the atmosphere and pollution are complex. weather conditions as well as local and distant emission sources. The location of atmospheric monitoring must also be taken into account when researching atmospheric chemistry. On the same day, atmospheric conditions will be very different between urban and ural sites, and often change rapidly according to the weather and seasonal variations. This means that it is vital to have long term, established monitoring stations that have many years of data to monitor background trends that can be successfully compared to short term, seasonal measurements of acute
pollution events.

Professor Schwab and his team maintain long-term air pollution Whiteface Mountain in the Adirondack Range and Pinnacle State Park, both within New York State. They provide a continuous air quality record reaching back more than 30 years. This provides an excellent dataset for identifying whether changes in air quality management and reductions in emissions have a noticeable effect on atmospheric pollutant concentrations. To make short-term measurements of localised pollution events, the team carries specific le laboratory. This that can measure the cony equipment that can measure the concentration of
aerosols along with various gas sensors.

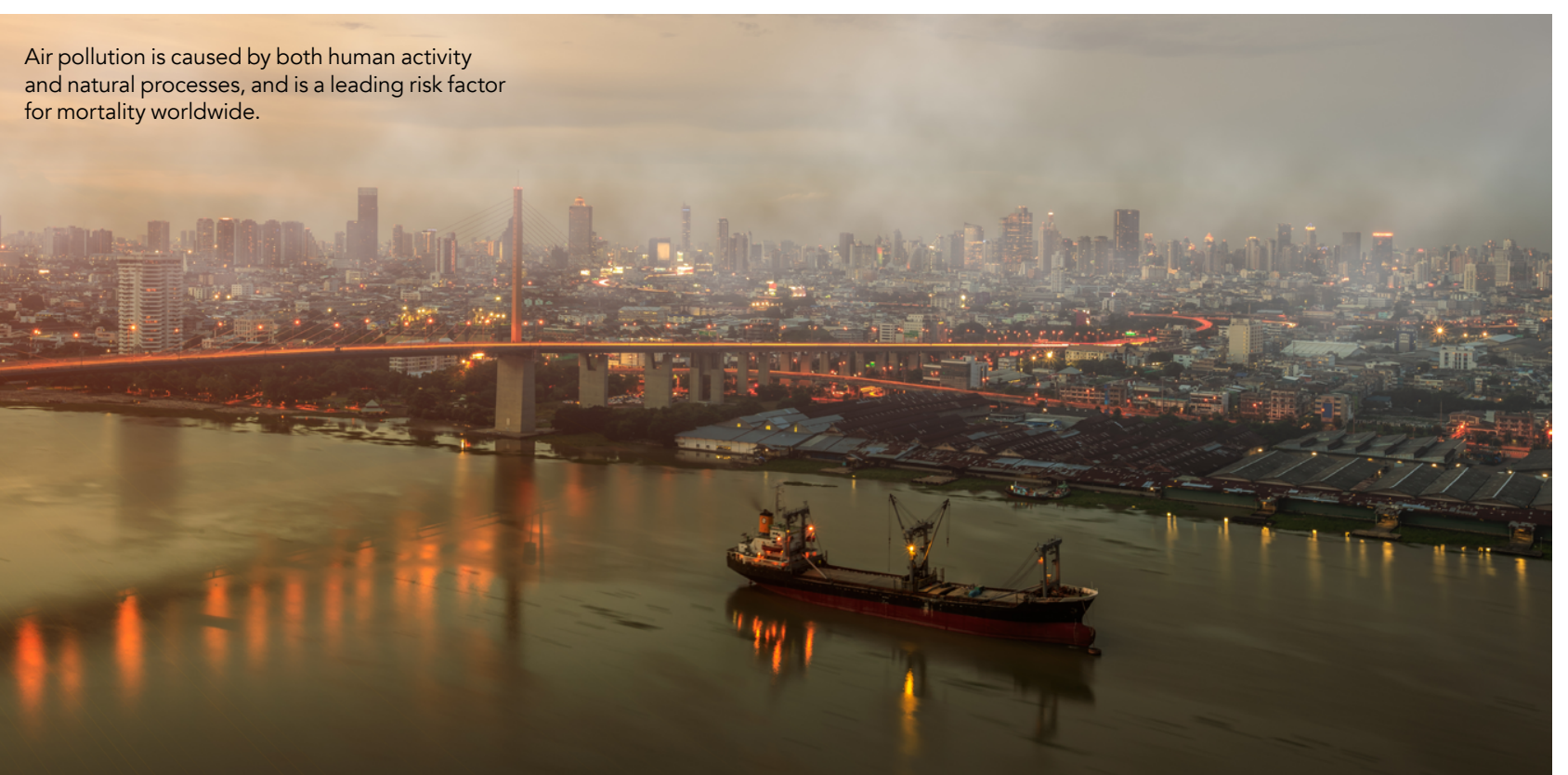

WHITEFACE MOUNTAIN MEASUREMENTS

Whiteface Mountain is an ideal location for long-term air quality measurements in New York State Urban locations and seashores often vary rapidly in atmospheric pollutants over short timescales due to changing sea breezes and human activity. Mountainous regions are more isolated and some of the best spots for long-term monitoring of atmospheric chemistry. They provide historical record of background levels for pollutants and enable researchers to see the effects of distant emission sources. The monitoring station on Whiteface Mountain is also frequently at cloud level, allowing the team to study precipitation, and atmon cherc poller,

Long-term monitoring stations are designed to gather information about the weather along with atmospheric pollutants. Professor Schwab and his te collect information about temperature and precipitation, as well as data about clouds and aerosols. The Whiteface monitoring station makes year-round observations of ozone, carbon monoxide, sulphur dioxide and nitrogen oxides pollution. Sulphur and nitrogen oxides can acidify water vapour if present in high concentrations. The station also monitors particulate matter by measuring the Total Suspended Particle load from air samples. This has been measured since on the reduction of sulphate as sulphur dioxide gas has reduced. It has also

Whe cloud droplet evaporates, these and the concentrtion of suphur dioxide

from regional emissions.

PROCESSING POLLUTANTS

IN CLOUDS and the local environment.

The team used a mobile laboratory on Whiteface Mountain for short-term monitoring of the physical and chemical

Monitoring air pollution is not a simple task. Air quality is controlled by varying pollutant types, emission sources, changes in weather, seasonality and location.

are home to simultaneous water vapour which affect the local envirenment Clouds are also vital within the climate system controlling how much of the Sun's radiation might reach the Earth's surface, which in turn affects Earth's ecosystems all the way to the ground level. Scientists are still learning about the complex interactions within clouds and how they interact with aerosol chemistry, but mountainous Mountain are key to understanding these processes.

Cloud formation relies on the presence of some particulate matter. Aerosols form the nuclei for cloud droplets, which in tum can dissolve other organic compounds. These undergo further chemical reactions understand this contribution to particle 2017. They com a one-week period laboratory data with the extensive data record from the Whiteface Mountain to show the
conditions at conditions at typical for the area.

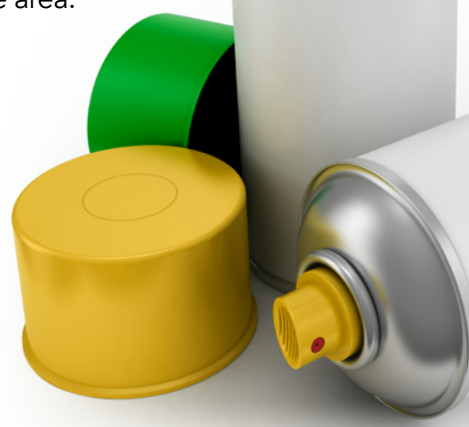




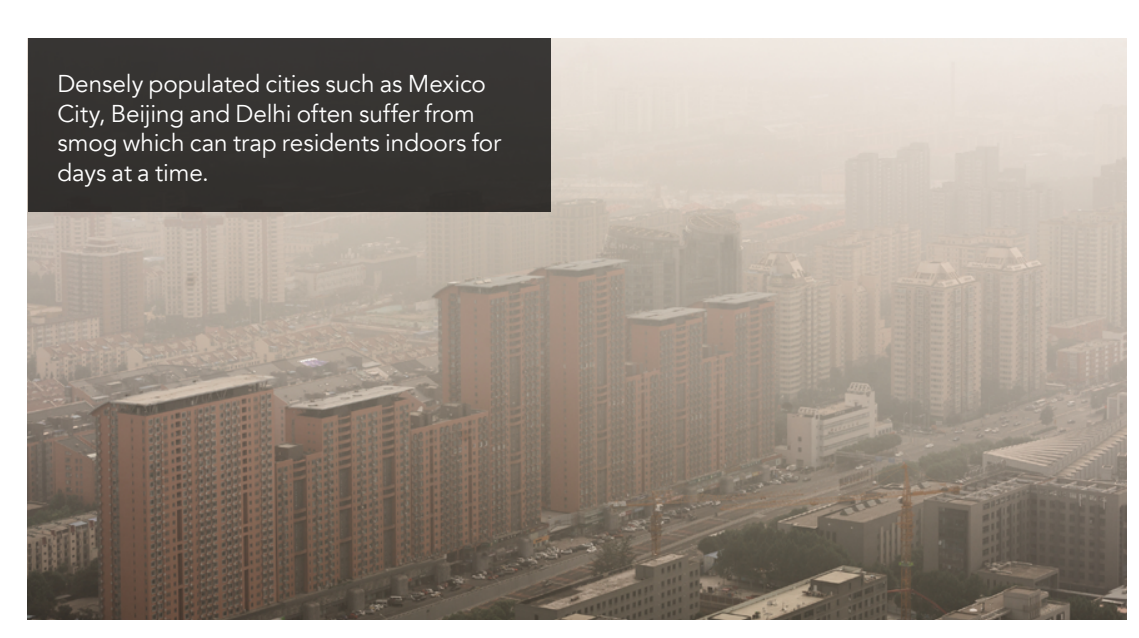

By modelling cloud processes, scientists can understand how the nature of atmospheric pollutants can change as the cloud environment drives chemical reactions.

The information gathered from the study concerning the role of aerosols has been used to improve the models used to simulate cloud processes in this area of the U.S.A. By modelling cloud processes, scientists can understand how the nature of atmospheric pollutants can change as the cloud environment drives chemical reactions.

\section{TROPOSPHERIC OZONE}

Tropospheric ozone is another type of atsospheric pollutant. The troposphere is the lowest section of the atmosphere, extending from the ground for up to 10 and when inhed is high concentrer causes breathing difficulties and lung

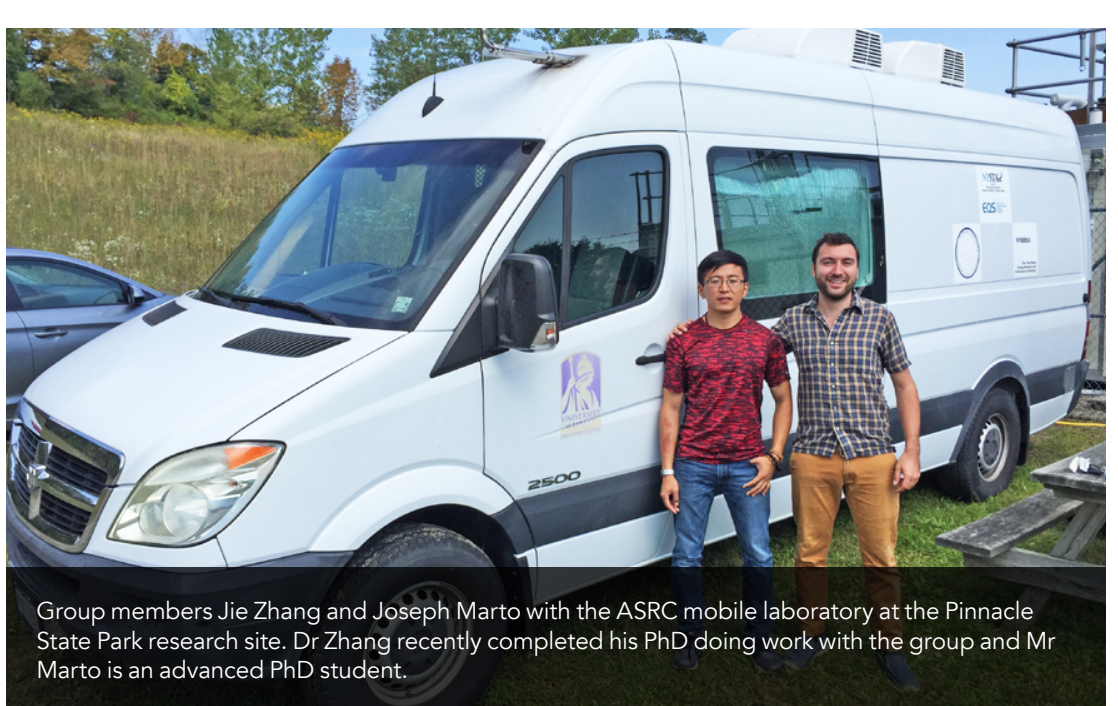

ozone production efficiency during The nummer between 2000 and 2017. decrease in nitrogen oxides throughou this period, and as expected the ozone production efficiency increased This was in non-urban, relatively clean areas. The findings suggest that managing nitrogen oxide emissions may no longer be the best way to limit ozone production in rural environments.

Professor Schwab and his colleagues have also been involved in investigating ozone formation around New York City. The team has been part of a multi-agenoy collaboration using the mobile laboratory along with fixed point measurements levels, nitrogen oxides and azoso levels, nitrogen oxides and aerosol concentrations within the metropolitan ummertime. The ozone circultion is further complicated here by sea breezes,

and the ozone levels frequently rise above those deemed as safe by the National Ambient Air Quality Standard. The team discovered that the ozone in the area is produced from a variety of sources, including from nitrogen oxide emitted by highway traffic from New York and blown downwind, and from gaseous compounds and aerosols from wildfire smoke originating much further afield in the western United States and Canad.

COMPLEXITIES OF

\section{ATMOSPHERIC POLLUTION}

Monitoring air pollution is not a simple task. Air quality results from a complex

compounds, emission sources, chan in weather seassion sources, changes making air pollution challenging to

understand and model. Maintaining long-term high-quality monitoring stations for sampling the atmosphere is vital for gathering enough informatio about the background levels to aid with policy development. It is the combination of long-term and short-term measurements that can then enable a deeper level of understanding of acute or seasonal pollution issues. Air pollution egulation depends upon accurate measurements and a clear understanding arow previous policies have affected air pollution levels. Only then can 作

\section{Behind the Research}

Prof James Schwab

E: jschwab@albany.edu T: $\quad$ +1-518-437-8754 (office) $\quad$ T: +1-518-469-8401 (mobile)

Research Objectives

Professor Schwab's research is focused on the role of air pollution measurements in the process of air quality management, and aims to help quide policy and practice.

\section{Detail}

\section{ASRC/CESTM} 251 Fuller Rd. Albany, NY 12203
USA Bio

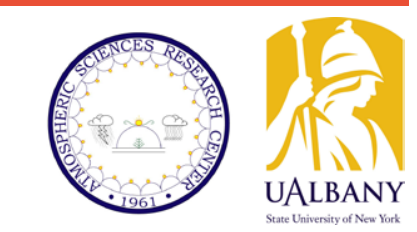

Prof James Schwab received his PhD from Harvard University and currently works at the Atmospheric Sciences Research Center, State University of New York at Albany. His research is in the field of Atmospheric Chemistry and Quality Measurements including the elucidation of sources and atmospheric processing of air pollutant species.

\section{Collaborators}

Environmental Conservation Division of Air Resources)

Marto, William May, Matthew Hesham Hassan, Joseph

John Spicer, and Jie Zhang

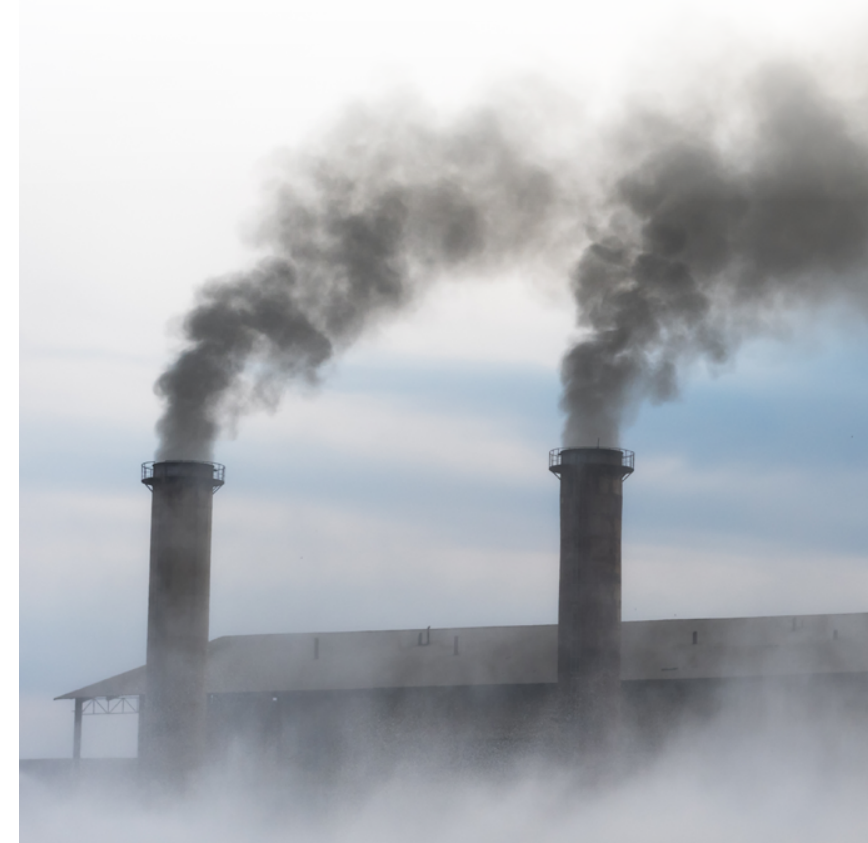

\section{References} Schwab, JJ, Wolfe, D, Casson, P, Brandt, R, Demeriian, KL,
Husain, L, Dutkiewicz, VA, Civerolo, KL \& Rattigan, OV. (2016).
Atmospheric science research at Whiteface Mountain, NY: Site Atmospheric science research at Whiteface Mountain, NY: Site description and history. Aerosol and Air
827-840. doi:10.4209/aagr.2015.05.0343

Zhang, J, Lance, S, Brandt, R, Marto, J, Ninneman, M \& Schwab, J. (2019) Observed below-cloud and cloud interstitial submicron aerosol chemical and physical
properties at Whiteface Mountain, New York, during August

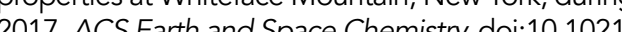
2017. ACS Earth and Space $C 7.4$
acsearthspacechem. 9600117

Ninneman, M, Demerjian, KL \& Schwab, JJ. (2019) Ozone production efficiencies at rural $\mathrm{New}$ York state locations: Atmospheres, 124. https://doi.org/10.1029/2018JD029932

\section{Personal Response}

What are your plans for future research in this area?

II The group plans to continue its important work of providing high quality, long-term data for use in air quality working on a number of challenging problems that address the chemistry and transport of pollution in our changing world. Developing countries need to establish and enforce air pollution regulations, and developed countries need to better address problems such as toxic small and low-cost sensors offer promise that we New begin to study air pollution on the micro-environment or neighbourhood scale. 